\title{
AVALIAÇÃO DA SELETIVIDADE DA MISTURA DE OXYFLUORFEN E AMETRYNE, APLICADA EM PRÉ OU PÓS-EMERGÊNCIA, A DEZ VARIEDADES DE CANA-DE- AÇÚCAR (CANA-PLANTA) ${ }^{1}$
}

\author{
EDIVALDO D. VELINI ${ }^{2}$, DAGOBERTO MARTINS ${ }^{2}$, LUIZ A. MANOEL ${ }^{3}$, SHIZUO MATSUOKA ${ }^{4}$, \\ JOSÉ C. TRAVAIN ${ }^{5}$ e JOSÉ C. CARVALHO ${ }^{6}$
}

\section{RESUMO}

O objetivo deste trabalho foi o de avaliar a seletividade da mistura de oxyfluorfen e ametryne, a dez cultivares de cana-de-açúcar. Utilizou-se as doses de 0,48 e $1,5 \mathrm{~kg}$ de i.a. / ha $(2,0$ e $3,01 \mathrm{de}$ p.c./ha), respectivamente. As cultivares utilizadas foram: RB 83-5089, RB 80-6043, RB 78-5148, RB 82-5336, RB 83-5486, RB 72-454, SP 791011, SP 70-1143, SP 71-1406 e SP 80-1842. Os herbicidas, em mistura de tanque, foram aplicados em pré ou pós-emergência ( 5 e 29 dias após o plantio, respectivamente). As testemunhas de cada variedade foram capinadas manualmente. O plantio foi feito nos dias 24 e 25/03/94. Nas parcelas com aplicação em préemergência verificou-se sintomas de intoxicação (avermelhamento e necrose) em $\mathbf{4 , 7 2 \%}$ (RB 83-5089) a $\mathbf{1 4 , 5 8 \%}$ (RB 82-5336) da área foliar da cultura; em pós-emergência os sintomas alcançaram entre 20,16\% (SP 71-1406) e 45,44\% (80-1842) da área foliar da cana. Com o crescimento da planta (a partir da oitava folha definitiva), as novas folhas emitidas não apresentaram sintomas de intoxicação. Não foram verificados efeitos dos herbicidas sobre 0 crescimento (emissão de folhas e altura das plantas), perfilhamento, produtividade e características tecnológicas dos colmos obtidos.

Palavras chave: Sintomas de intoxicação, herbicida.

\section{ABSTRACT}

\section{Selectivity of oxyfluorfen and ametryn in sugarcane varieties}

The objective of this research was the evaluation of the selectivity of the herbicides oxyfluorfen and ametryn, in tank mixture, to ten sugarcane varieties. It were used the rates of 0.48 and $1.5 \mathrm{~kg}$ a.i. / ha, respectively. Herbicides were applied in pre or post-emergence ( 5 or 29 days after planting). Checks were hand-weeded. It were used the varieties RB 83-5089, RB 80-6043, RB 78-5148, RB 82-5336, RB 83-5486, RB 72454, SP 79-1011, SP 70-1143, SP 71-1406 e SP 80-1842. Sugarcane was planted in
$03 / 24^{\text {th }}$ and $25^{\text {th }} / 1994$. In pre-emergence plots, intoxication symptoms (spots with brown color or dead tissues) were observed in 4,72\% (RB 835089 ) to $\mathbf{1 4 , 5 8 \%}$ (RB 82-5336) of the leaf area. In post-emergence plots, symptoms were observed in $\mathbf{2 0 , 1 6 \%}$ (SP 71-1406) to $\mathbf{4 5 , 4 4 \%}$ (80-1842) of the total leaf area. As plant grew, intoxication became weaker. New leaves, after the eighth one, showed no symptoms. The herbicides did not affect sugarcane growth (number of leaves, tillering and

\footnotetext{
${ }^{1}$ Recebido para publicação em 23/11/98 e na forma revisada em 14/04/99.

${ }^{2}$ Professor Assistente de Doutor, Depto. Produção Vegetal, FCA/UNESP. C.P. 237, CEP 18603 -970 Botucatu, SP/Brasil. 3 Usina Açucareira São Manoel. C.P. 127, CEP: 18650-000, São Manoel/SP.

${ }^{4}$ Centro de Ciências Agrárias / UFSCAR. Rodovia Washington Luis, km 235. C.P. 676, CEP: 13565 -905, São Carlos/SP.

${ }^{5}$ Rohm and Haas Química Ltda. Rua Tamoios, 421, apto. 14, Jardim Santa Cruz, CEP: 14020-700, Ribeirão Preto/S P.

${ }^{6}$ Rohm and Haas Química Ltda. C.P. 66, CEP: 13140-000, Paulínia/SP.
} 
plant height), the yield and the quality of the culms.
Key words: Intoxication symptoms, herbicide.

\section{INTRODUÇÃO}

O oxyfluorfen, é um herbicida de utilização recente em cana-de-açúcar. Proporciona altos níveis de controle de uma série de plantas daninhas de grande importância nessa cultura, destacando-se Digitaria horizontalis Willd. e Brachiaria decumbens Stapf. Apresenta menor solubilidade e menor persistência do que alguns de seus principais concorrentes nesta cultura.

Segundo Almeida \& Rodrigues (1998) o oxyfluorfen apresenta como mecanismo de ação principal, a deterioração das membranas dos tecidos atingidos, sendo preferencialmente absorvido pelas folhas. Não atua sobre as raízes das plantas. Ainda segundo os autores, em decorrência da baixa solubilidade e da elevada adsorção, o oxyfluorfen é praticamente imóvel no solo. A decomposição ocorre essencialmente por fotólise, sendo desprezível a ação de microorganismos. Contribui para a grande importância do processo fotolítico, o posicionamento superficial do herbicida no solo, em razão de sua pequena lixiviação.

A mistura com ametryne amplia o espectro de controle e permite a aplicação em pósemergência das plantas daninhas, aspecto este, sobremaneira importante em cana-soca.

A presença de sintomas de intoxicação visualmente detectáveis tem levado técnicos de campo a evitar o uso do oxyfluorfen, preocupados com possíveis reduções de produtividade da cultura. Muitos técnicos admitem, empiricamente, correspondência direta entre a intensidade dos sintomas visuais de intoxicação e possíveis reduções de produtividade. Contudo, tal correlação ainda não foi estabelecida, de modo específico e segundo critérios científicos, para o oxyfluorfen.

O sintoma característico de intoxicação da cana-de-açúcar com oxyfluorfen corresponde a manchas de cor marrom-avermelhadas, localizadas nos pontos em que as folhas da cultura entram em contato com o herbicida. Tais manchas podem ou não evoluir para necroses. Os sintomas são restritos aos pontos de contato, na medida em que o oxyfluorfen não sofre redistribuição nas plantas. Esta ausência de mobilidade resulta de sua baixa solubilidade $(<0,1 \mathrm{ppm})$, condicionando ao mesmo, elevado coeficiente de partição $\left(\mathrm{K}_{\mathrm{OW}}\right)$.

O sintoma de intoxicação da cana-deaçúcar pela ametryne corresponde à clorose seguida de necrose, iniciando-se pelos bordos das folhas. Em aplicações de pós-emergência os sintomas podem também apresentarem-se restritos ou serem mais acentuados nos pontos de contato da calda herbicida com as folhas. A ametryne apresenta eficiente absorção radicular.

Entendendo-se por seletividade a capacidade de um determinado herbicida eliminar as plantas daninhas que se encontram em uma cultura sem reduzir-lhe a produtividade, torna-se evidente que esta não pode ser determinada apenas pela verificação, ou não, de sintomas visuais de intoxicação. Há a necessidade de avaliar os efeitos de tais sintomas visualmente detectáveis e de outros imperceptíveis, sobre o crescimento e produtividade da cultura.

Estudos realizados com herbicidas de ação localizada indicam que a cultura da cana-deaçúcar pode tolerar até $27 \%$ de comprometimento da sua área foliar sem que isso implique em reduções de produtividade (Velini et al., 1993). De modo complementar, estão disponíveis na literatura, vários trabalhos reportando o comportamento diferencial de genótipos das mais variadas culturas, frente aos mais diversos herbicidas. Especificamente para cana-de-açúcar, são escassos os trabalhos de seletividade, destacando-se os trabalhos de Velini et al. (1993), Velini et al. (1996) e Constantin (1997).

Para ser recomendado de forma definitiva e indiscriminada para uma determinada cultura, um herbicida em teste deve demonstrar seletividade aos cultivares mais comuns da mesma. A rápida renovação das variedades de 
cana-de-açúcar em uso, torna o trabalho de avaliação da sensibilidade de novas cultivares praticamente contínuo, e deveria ser realizado indistintamente tanto para herbicidas novos quanto para os tradicionalmente utilizados na cultura. Este trabalho teve por objetivo avaliar a seletividade da mistura oxyfluorfen + ametryne, aplicada em pré ou pós-emergência, a dez variedades de cana de açúcar.

\section{MATERIAL E MÉTODOS}

Procurou-se, neste trabalho, determinar as condições necessárias para que a seletividade da mistura oxyfluorfen + ametryne à cana de açúcar, fosse plenamente preservada. Dentre todas as variáveis que poderiam ser estudadas, foram consideradas como prioritárias, variedades e épocas de aplicação da mistura. Foram utilizados os herbicidas comerciais Goal (240 g i.a. / 1) e Gesapax 500 (500 g i.a. /l), nas doses de 2 e 31 de p.c. / ha, respectivamente. A mistura dos mesmos foi feita no reservatório de calda do pulverizador, momentos antes da aplicação.

Os 30 tratamentos considerados corresponderam às combinações entre 10 variedades de cana-de-açúcar e três distintas condições em termos de aplicação da mistura dos herbicidas. Foram utilizadas as variedades RB 83 5089, RB 80 6043, RB 78 5148, RB 82 5336, RB 83 5486, RB 72 454, SP 79 1011, SP 70 1143, SP 711406 e SP 801842 . Foram as seguintes, as três condições em termos de aplicação dos herbicidas: a) aplicação da mistura oxyfluorfen + ametryne em pré-emergência, logo após o plantio da cultura; b) aplicação da mistura em pós-emergência inicial da cultura; c) tratamento testemunha em que não se aplicou herbicidas. Todas as plantas daninhas que ocorreram na área experimental, mesmo em subparcelas que receberam aplicação dos herbicidas, foram controladas manualmente.

Para que os efeitos dos herbicidas sobre a cultura fossem avaliados com maior precisão, foram utilizadas parcelas subdivididas. Considerou-se nas parcelas, as variedades de cana- de-açúcar. Às subparcelas, foram aplicados as três distintas condições em termos de aplicação dos herbicidas e controle das plantas daninhas. O delineamento utilizado foi o de blocos casualizados com 4 repetições. Cada parcela e subparcela constituíram-se de 15 e 5 linhas da cultura com $8 \mathrm{~m}$ de comprimento, respectivamente.

O ensaio foi conduzido na Usina São Manoel, localizada no município de São Manoel SP. O plantio da cultura foi realizado nos dias 24 e 25 de março de 1994. O preparo do solo, o sulcamento e a adubação foram realizados mecanicamente adotando-se as técnicas usuais na referida Usina. O plantio foi feito manualmente, utilizando-se quantidades uniformes de colmos em todas as linhas de cada cultivar. O espaçamento entre linhas de plantio foi de $1,10 \mathrm{~m}$. O solo da área experimental apresenta textura arenosa com teor de matéria orgânica de $1,52 \%$ e CTC de 4,08 meq / $100 \mathrm{~g}$ de solo.

As aplicações em pré e pós-emergência foram realizadas nos dias 30 de março e 21 de abril de 1994, respectivamente. As duas operações foram feitas entre as 16 e 18 horas, na ausência de ventos, temperaturas médias de 25 e $23{ }^{\circ} \mathrm{C}$ e umidades relativas médias de $58 \%$ e $65 \%$, também de forma respectiva.

Nas duas aplicações utilizou-se um pulverizador costal pressurizado a $\mathrm{CO}_{2}$, equipado com bicos XR 80.02, operando a 40 libras / $\mathrm{pol}^{2}$ $\left(2,809 \mathrm{~kg} / \mathrm{cm}^{2}\right)$. O volume de calda aplicado foi de $2421 /$ ha. Quando da aplicação em préemergência, o solo encontrava-se seco, mas as primeiras chuvas na área ocorreram dois dias após a operação. $\mathrm{Na}$ aplicação em pós-emergência, o solo encontrava-se úmido.

Nos dias 5 e 31 de maio de 1996, avaliouse a toxicidade da mistura à cultura, atribuindo-se notas para a porcentagem de área de cada folha de 16 plantas de cada subparcela, com sintomas de intoxicação (avermelhamento associado ou seguido de necrose). Foram realizadas outras avaliações destas mesma característica, mas a utilização das mesmas foi comprometida pela ocorrência de geada no dia 26 de junho e de longo 
período de seca após esta data. Nos 118 dias compreendidos entre 26 de junho e 20 de outubro, a precipitação acumulada foi de apenas $25,5 \mathrm{~mm}$. Os danos provocados pela geada foram pequenos, havendo somente a queimadura de parte das folhas, mas os sintomas confundiram-se com os sintomas de intoxicação dos herbicidas impossibilitando a utilização dos resultados obtidos.

A colheita foi feita nos dias 2 e 3 de agosto de 1995. Foram contados e pesados todos os colmos presentes nas subparcelas. As avaliações referentes à qualidade industrial dos colmos foi feita segundo o procedimento usual na Usina São Manoel. Determinou-se, também, o comprimento de cada um dos entrenós de 15 colmos selecionados ao acaso na área útil das parcelas. São apresentados, neste trabalho, os dados referentes ao número médio de colmos por metro, comprimento e peso médio dos colmos, produtividade de colmos, conteúdo de açúcar dos colmos e produtividade de açúcar. São, ainda, apresentadas informações referentes ao comprimento dos vários entrenós da cana-deaçúcar.

Os resultados obtidos foram submetidos a análise de variância. A comparação das médias das três condições em termos de aplicação dos herbicidas (testemunha, pré e pós-emergência) para todo o conjunto de variedades e para cada uma delas, foi feita com o auxílio do teste "t" ao nível de 5\% de probabilidade.

\section{RESULTADOS E DISCUSSÃO}

Na Tabela 1 são apresentados os números médios de folhas das 10 cultivares quando da aplicação em pós-emergência e quando da primeira avaliação da intensidade de intoxicação, 12 dias mais tarde. Observa-se que, nos doze dias após a aplicação, a emissão de novas folhas foi bastante rápida, alcançando valores próximos a três folhas por planta, em média. Todas as variedades encontravam-se em estágio bastante inicial de desenvolvimento quando da aplicação.

TABELA 1. Número médio de folhas quando da aplicação dos herbicidas oxyfluorfen + ametryne em pós emergência e 12 dias após, quando foi feita a primeira avaliação de intoxicação da cultura.

\begin{tabular}{cccc}
\hline Variedades & \multicolumn{2}{c}{ Número médio de Folhas } & $\begin{array}{c}\text { Aumento do número } \\
\text { de folhas }\end{array}$ \\
\cline { 2 - 3 } & Na aplicação & Na avaliação & 3,07 \\
RB 83-5089 & 1,25 & 4,32 & 2,81 \\
RB 80-6043 & 0,70 & 3,51 & 2,75 \\
RB 78-5148 & 1,74 & 4,49 & 3,18 \\
RB 82-5336 & 0,76 & 3,94 & 2,56 \\
RB 83-5486 & 1,54 & 4,10 & 2,79 \\
RB 72-454 & 1,26 & 4,05 & 2,84 \\
SP 79-1011 & 1,75 & 4,59 & 2,51 \\
SP 70-1143 & 1,88 & 4,39 & 2,66 \\
SP 71-1406 & 1,15 & 3,81 & 3,27 \\
SP 80-1842 & 1,68 & 4,95 & 2,85 \\
\hline Médias & 1,37 & 4,22 & \\
\hline
\end{tabular}


$\mathrm{Na}$ Tabela 2 são apresentados os resultados da primeira avaliação de intoxicação da cultura. Uma análise preliminar dos sintomas indicou que a intoxicação da cultura foi ocasionada quase que exclusivamente pelo oxyfluorfen; não tendo sido verificados sintomas característicos da intoxicação pela ametryne, isoladamente.

Ficou evidente que o oxyfluorfen pode entrar em contato com as folhas da cultura quando da brotação (esporão e primeiras folhas somente), pela interceptação das gotas de pulverização (folhas já emitidas quando é feita a aplicação em pós-emergência) e através do carregamento de solo tratado por respingos de chuva (atinge preferencialmente as folhas próximas ao solo).

Na primeira avaliação calculou-se o nível médio de intoxicação de plantas com diferentes números de folhas. Verifica-se que nas parcelas com aplicação em pré-emergência, os sintomas foram mais intensos nas plantas mais velhas. A justificativa refere-se ao fato de que os sintomas resultantes do carregamento de solo tratado até as folhas, pelas gotas de chuva, acumulam-se ao longo do tempo, fazendo com que as plantas mais velhas apresentem maior número de lesões desse modo originadas. Os baixos níveis de intoxicação em plantas jovens indicam a reduzida importância da absorção durante a passagem da planta em brotação pelas regiões do solo que contêm os herbicidas.

Quando a aplicação foi feita em pósemergência, a intensidade dos sintomas foi tanto maior quanto mais velhas as plantas. Neste caso, a justificativa refere-se ao fato de as plantas mais velhas apresentarem maior área foliar e maior interceptação da calda no momento da aplicação. A precipitação acumulada no período entre a aplicação e a primeira avaliação foi de apenas $5,5 \mathrm{~mm}$ indicando que, até esta data, a intoxicação por partículas de solo carregadas por respingos de chuva pode ser considerada desprezível.

Considerando somente a aplicação em pós-emergência, o coeficiente de correlação entre o número médio de folhas quando da aplicação e a porcentagem de área foliar lesionada, para cada cultivar, foi de $0,7959 * *\left(R^{2}=0,6334\right)$, indicando que os sintomas foram, em geral, mais intensos nas variedades que apresentavam maior número de folhas no momento da aplicação.

O coeficiente de correlação entre as porcentagens de intoxicação, para cada variedade, quando a aplicação foi feita em pré e pósemergência, foi de apenas $0,00000328^{\text {ns }}$ $\left(\mathrm{R}^{2}=1,07 \times 10^{-11}\right)$ indicando independência entre as duas características.

Fica evidente que os sintomas de intoxicação foram mais severos quando a aplicação foi feita em pós-emergência. Considerando somente esta modalidade de aplicação, os sintomas foram mais intensos quanto maior o número de folhas no momento da pulverização.

Na Tabela 3 são apresentados os resultados referentes à segunda avaliação de intoxicação das plantas de cana. Neste caso, a porcentagem da área foliar com sintomas de intoxicação foi calculada de forma discriminada para cada uma das folhas da cultura. A avaliação foi feita de modo ascendente; a primeira folha é a que se encontrava mais próxima ao solo. Nas subparcelas com aplicação em pré-emergência os sintomas já haviam praticamente desaparecido, representando, em termos médios para as 10 variedades, $3,52 \%$ da área foliar da cana-deaçúcar. Nas subparcelas em que a aplicação foi feita em pós-emergência os sintomas corresponderam, também em termos médios, a $12,42 \%$ da área foliar da cultura. Embora a intensidade de intoxicação tenha regredido nas duas modalidades de aplicação, os sintomas mantiveram-se mais intensos nas subparcelas com aplicação em pós-emergência. A redução da porcentagem da área foliar com sintomas deveu-se à expansão da área foliar total da cultura e não à redução da área das lesões.

Deve ser destacado que as folhas mais novas apresentaram baixos níveis de intoxicação, nas duas modalidades de aplicação. 
TABELA 2. Porcentagem da área foliar com sintomas de intoxicação pelos herbicidas oxyfluorfen e ametryne utilizados em mistura. Avaliação realizada em 05 de maio de 1994, aos 39 e 12 dias após a aplicação em pré e pós-emergência, respectivamente.

\begin{tabular}{|c|c|c|c|c|c|c|c|c|c|}
\hline \multirow{2}{*}{$\begin{array}{l}\text { Épocas de } \\
\text { aplicação }\end{array}$} & \multirow{2}{*}{ Variedades } & \multicolumn{7}{|c|}{ Plantas com diferentes números de folhas } & \multirow{2}{*}{ Médias } \\
\hline & & 2 & 3 & 4 & 5 & 6 & 7 & 8 & \\
\hline \multirow{11}{*}{ Pré } & RB 83-5089 & 0,00 & 3,20 & 4,40 & 7,70 & 3,30 & 5,90 & $\overline{---}$ & 4,72 \\
\hline & RB 80-6043 & 0,00 & 3,00 & 14,20 & 19,40 & --- & --- & --- & 10,10 \\
\hline & RB 78-5148 & --- & 6,80 & 5,20 & 13,50 & 16,10 & --- & --- & 9,23 \\
\hline & RB 82-5336 & 0,00 & 9,30 & 12,20 & 21,10 & 30,80 & --- & --- & 14,58 \\
\hline & RB 83-5486 & 3,20 & 11,10 & 15,20 & 12,70 & 17,20 & 8,60 & --- & 12,92 \\
\hline & RB 72-454 & 0,00 & 3,50 & 4,20 & 10,90 & 12,20 & --- & --- & 5,48 \\
\hline & SP 79-1011 & 0,00 & 7,10 & 6,40 & 13,40 & 14,20 & --- & --- & 10,10 \\
\hline & SP 70-1143 & 22,50 & 3,80 & 11,20 & 16,70 & 15,30 & 13,30 & --- & 12,21 \\
\hline & SP 71-1406 & 1,30 & 8,90 & 10,80 & 10,60 & 18,30 & --- & --- & 10,05 \\
\hline & SP 80-1842 & 0,00 & 0,40 & 12,30 & 10,80 & 9,40 & 16,20 & --- & 11,11 \\
\hline & Médias & 3,00 & 5,71 & 9,61 & 13,68 & 15,20 & 11,00 & --- & 10,05 \\
\hline \multirow{11}{*}{ Pós } & RB 83-5089 & --- & 6,50 & 19,00 & 44,90 & 40,60 & 40,70 & -- & 30,39 \\
\hline & RB 80-6043 & 1,30 & 13,20 & 41,90 & 38,80 & --- & --- & --- & 30,16 \\
\hline & RB 78-5148 & 0,00 & 13,30 & 31,90 & 39,30 & 46,30 & 53,40 & --- & 38,03 \\
\hline & RB 82-5336 & --- & 7,10 & 22,00 & 33,40 & 52,50 & --- & --- & 24,37 \\
\hline & RB 83-5486 & --- & 18,30 & 31,90 & 41,00 & 46,50 & 39,70 & --- & 34,73 \\
\hline & RB 72-454 & 5,00 & 7,10 & 23,00 & 42,90 & 41,50 & 37,90 & --- & 33,03 \\
\hline & SP 79-1011 & 6,50 & 12,50 & 38,60 & 47,10 & 43,10 & 38,50 & --- & 41,92 \\
\hline & SP 70-1143 & --- & 25,50 & 37,70 & 42,50 & 47,20 & --- & --- & 41,12 \\
\hline & SP 71-1406 & 1,25 & 8,30 & 25,30 & 33,70 & 0,00 & --- & --- & 20,16 \\
\hline & SP $80-1842$ & --- & 15,00 & 37,00 & 50,50 & 48,00 & 46,40 & 58,80 & 45,44 \\
\hline & Médias & 2,81 & 12,68 & 30,83 & 41,41 & 40,63 & 42,77 & 58,80 & 33,94 \\
\hline
\end{tabular}

As justificativas são o distanciamento em relação ao solo, dificultando a intoxicação causada pelos respingos de chuva e o fato de ainda não estarem abertas quando da aplicação em pósemergência. Este fato indica que a absorção radicular teve pequena importância em termos de intoxicação da cultura e que os sintomas mantiveram-se restritos aos pontos de contato dos herbicidas com as folhas. A ocorrência de sintomas localizados já era esperada, na medida em não foram verificados sintomas de intoxicação pela ametryne; ou seja, as lesões nas folhas deveram-se, preferencial ou exclusivamente, à ação do oxyfluorfen, um herbicida imóvel nas plantas.
Os coeficientes de correlação entre as porcentagens da área foliar com sintomas, para cada variedade, nas duas avaliações, foram de $0,6735 * *\left(R^{2}=0,4560\right)$ e $0,5709 * *\left(R^{2}=0,3259\right)$, quando a aplicação foi feita em pré e pósemergência, respectivamente. Apesar da significância, os baixos coeficientes de determinação indicam uma pequena dependência entre os resultados obtidos nas duas avaliações. Em termos práticos este comportamento indica, por sua vez, que as variedades podem apresentar padrões diferenciados de crescimento e superação da intoxicação e que este padrão de recuperação pouco depende da intensidade inicial de intoxicação. 
TABELA 3. Porcentagem da área foliar com sintomas de intoxicação pelos herbicidas oxyfluorfen e ametryne utilizados em mistura. Avaliação realizada em 31 de maio de 1994, aos 65 e 38 dias após a aplicação em pré e pós-emergência, respectivamente.

\begin{tabular}{|c|c|c|c|c|c|c|c|c|c|c|c|}
\hline \multirow{2}{*}{$\begin{array}{l}\text { Épocas de } \\
\text { Aplicação }\end{array}$} & \multirow{2}{*}{ Variedades } & \multicolumn{9}{|c|}{ Folhas - avaliação ascendente nas plantas } & \multirow{2}{*}{ Médias } \\
\hline & & 1 & 2 & 3 & 4 & 5 & 6 & 7 & 8 & 9 & \\
\hline \multirow{11}{*}{ Pré } & RB 83-5089 & 10,00 & 3,40 & 2,00 & 1,00 & 0,30 & 0,60 & 0,90 & 0,60 & 0,60 & 2,20 \\
\hline & RB 80-6043 & 1,60 & 1,10 & 0,20 & 1,20 & 1,30 & 1,20 & --- & --- & --- & 1,10 \\
\hline & RB 78-5148 & 8,00 & 7,90 & 2,50 & 0,90 & 0,50 & 1,00 & 1,00 & 0,90 & --- & 2,80 \\
\hline & RB 82-5336 & 22,50 & 16,50 & 2,10 & 0,80 & 1,10 & 3,00 & 3,50 & 2,50 & --- & 6,50 \\
\hline & RB 83-5486 & 13,80 & 11,20 & 4,10 & 0,50 & 0,30 & 1,40 & 1,20 & 1,60 & --- & 4,30 \\
\hline & RB 72-454 & 8,00 & 5,60 & 0,80 & 0,50 & 0,30 & 0,60 & 0,60 & 0,30 & --- & 2,10 \\
\hline & SP 79-1011 & 16,00 & 10,90 & 2,50 & 3,30 & 1,90 & 2,20 & 1,40 & & --- & 5,50 \\
\hline & SP 70-1143 & 15,00 & 11,20 & 4,80 & 2,20 & 0,80 & 1,80 & 1,50 & 1,30 & --- & 4,80 \\
\hline & SP 71-1406 & 3,30 & 11,70 & 3,60 & 1,00 & 1,30 & 1,30 & 1,00 & & --- & 3,30 \\
\hline & SP $80-1842$ & 0,00 & 3,80 & 10,60 & 1,40 & 1,70 & 0,90 & 2,00 & 1,90 & 1,20 & 2,60 \\
\hline & Médias & 9,82 & 8,33 & 3,32 & 1,28 & 0,95 & 1,40 & 1,46 & 1,30 & 0,90 & 3,52 \\
\hline \multirow{11}{*}{ Pós } & RB 83-5089 & 1,00 & 100,0 & 44,90 & 5,10 & 11,60 & 2,40 & 2,70 & 2,40 & 1,30 & 21,30 \\
\hline & RB 80-6043 & 17,50 & 6,70 & 3,80 & 6,80 & 6,40 & 3,10 & --- & --- & --- & 7,40 \\
\hline & RB 78-5148 & 14,70 & 20,80 & 7,30 & 3,50 & 4,00 & 3,10 & 1,70 & --- & --- & 7,90 \\
\hline & RB 82-5336 & 0,00 & 19,20 & 8,40 & 3,70 & 4,90 & 9,60 & 9,90 & 5,90 & --- & 7,70 \\
\hline & RB 83-5486 & 5,00 & 20,70 & 14,40 & 2,80 & 3,60 & 6,90 & 4,60 & 2,50 & --- & 7,60 \\
\hline & RB 72-454 & 18,70 & 7,50 & 0,90 & 2,60 & 4,20 & 3,20 & 2,10 & & --- & 5,60 \\
\hline & SP 79-1011 & 85,00 & 46,80 & 39,70 & 20,70 & 9,40 & 6,30 & 8,40 & 4,20 & --- & 27,60 \\
\hline & SP 70-1143 & --- & 32,40 & 20,90 & 10,70 & 4,20 & 6,80 & 6,90 & 3,40 & --- & 12,20 \\
\hline & SP 71-1406 & 15,00 & 8,80 & 5,70 & 3,20 & 3,30 & 3,40 & --- & --- & --- & 5,90 \\
\hline & SP $80-1842$ & 88,30 & 41,80 & 10,60 & 9,40 & 5,80 & 5,00 & 4,70 & 2,30 & --- & 21,00 \\
\hline & Médias & 27,24 & 30,47 & 15,66 & 6,85 & 5,74 & 4,98 & 5,13 & 3,45 & 1,30 & 12,42 \\
\hline
\end{tabular}

Na Tabela 4, são apresentados os resultados referentes ao número, comprimento e peso médio de colmos. Estas três características não foram afetadas pela aplicação da mistura de oxyfluorfen e ametryne em pré ou pós-emergência em qualquer das variedades estudadas.

Avaliou-se, também por ocasião da colheita, o comprimento médio de cada entrenó das dez variedades estudadas. O objetivo foi o de determinar se os entrenós emitidos enquanto estiveram presentes os sintomas de intoxicação tiveram seus comprimentos reduzidos. As médias para todas as variedades são mostrados nas
Figuras 1 a 3.

A análise das três figuras, sobretudo das Figuras 2 e 3, indica que os primeiros nove e dois entrenós emitidos nas parcelas com aplicação dos herbicidas em pré e pós-emergência, respectivamente, apresentaram comprimentos menores do que os entrenós correspondentes, nas parcelas testemunhas. Como consequência deste efeito, os colmos das parcelas tratadas em pré ou pós-emergência mantiveram-se menores do que os colmos das testemunhas até a emissão do $19^{\circ}$ e do $3^{0}$ entrenó, também de modo respectivo. 
TABELA 4. Resultados referentes ao perfilhamento, comprimento e peso médio de colmos.

\begin{tabular}{|c|c|c|c|c|}
\hline Variedades & $\begin{array}{l}\text { Condições de } \\
\text { Aplicação } \\
\end{array}$ & $\begin{array}{c}\text { Número de colmos por } \\
\text { metro }\end{array}$ & $\begin{array}{c}\text { Comprimento de } \\
\text { colmos }(\mathrm{m})\end{array}$ & $\begin{array}{c}\text { Peso de colmos } \\
(\mathrm{kg})\end{array}$ \\
\hline \multirow{3}{*}{ RB 83-5089 } & Testemunha & 9,79 & 2,29 & 1,21 \\
\hline & Pré-emergência & 10,13 & 2,24 & 1,14 \\
\hline & Pós-emergência & 10,28 & 2,21 & 1,12 \\
\hline \multirow{3}{*}{ RB 80-6043 } & Testemunha & 8,47 & 1,91 & 1,11 \\
\hline & Pré-emergência & 10,20 & 1,96 & 0,99 \\
\hline & Pós-emergência & 9,04 & 1,92 & 1,08 \\
\hline \multirow{3}{*}{ RB 78-5148 } & Testemunha & 8,53 & 2,07 & 1,19 \\
\hline & Pré-emergência & 10,06 & 2,20 & 1,10 \\
\hline & Pós-emergência & 8,67 & 2,09 & 1,21 \\
\hline \multirow{3}{*}{ RB 82-5336 } & Testemunha & 9,68 & 2,11 & 1,04 \\
\hline & Pré-emergência & 9,46 & 1,96 & 1,07 \\
\hline & Pós-emergência & 9,71 & 1,96 & 0,98 \\
\hline \multirow{3}{*}{ RB 83-5486 } & Testemunha & 6,91 & 1,79 & 1,36 \\
\hline & Pré-emergência & 8,49 & 1,76 & 1,17 \\
\hline & Pós-emergência & 8,48 & 1,93 & 1,22 \\
\hline \multirow{3}{*}{ RB 72-454 } & Testemunha & 9,36 & 1,95 & 1,12 \\
\hline & Pré-emergência & 9,89 & 1,99 & 1,10 \\
\hline & Pós-emergência & 9,46 & 1,95 & 1,17 \\
\hline \multirow{3}{*}{ SP 79-1011 } & Testemunha & 9,67 & 1,73 & 0,98 \\
\hline & Pré-emergência & 9,93 & 1,79 & 1,01 \\
\hline & Pós-emergência & 9,11 & 1,71 & 1,07 \\
\hline \multirow{3}{*}{ SP 70-1143 } & Testemunha & 10,05 & 1,73 & 0,83 \\
\hline & Pré-emergência & 10,20 & 1,70 & 0,85 \\
\hline & Pós-emergência & 10,08 & 1,74 & 0,86 \\
\hline \multirow{3}{*}{ SP 71-1406 } & Testemunha & 8,08 & 1,96 & 1,12 \\
\hline & Pré-emergência & 10,39 & 1,97 & 0,94 \\
\hline & Pós-emergência & 8,53 & 2,06 & 1,14 \\
\hline \multirow{3}{*}{ SP $80-1842$} & Testemunha & 8,58 & 2,34 & 1,08 \\
\hline & Pré-emergência & 9,37 & 2,34 & 1,04 \\
\hline & Pós-emergência & 8,52 & 2,25 & 1,05 \\
\hline \multirow{3}{*}{ Médias } & Testemunha & 8,91 & 1,99 & 1,10 \\
\hline & Pré-emergência & 9,81 & 1,99 & 1,04 \\
\hline & Pós-emergência & 9,19 & 1,98 & 1,09 \\
\hline \multirow{14}{*}{ Valores de F: } & Blocos & $1,35^{\mathrm{NS}}$ & $10,21 * *$ & $2,82^{\mathrm{NS}}$ \\
\hline & Variedades (V) & $3,86^{* *}$ & $13,51 * *$ & $15,28 * *$ \\
\hline & Condições (C) & $8,07 * *$ & $0,04^{\mathrm{NS}}$ & $3,54^{*}$ \\
\hline & $\mathrm{V} \times \mathrm{C}$ & $0,95^{\mathrm{NS}}$ & $0,54^{\mathrm{NS}}$ & $0,92^{\mathrm{NS}}$ \\
\hline & $C d R B$ 83-5089 & $0,24^{\mathrm{NS}}$ & $0,23^{\mathrm{NS}}$ & $0,68^{\mathrm{NS}}$ \\
\hline & $C d R B$ 80-6043 & $2,95 \mathrm{NS}$ & $0,12^{\mathrm{NS}}$ & $1,31^{\mathrm{NS}}$ \\
\hline & $C d R B 78-5148$ & $2,69 \mathrm{NS}$ & $0,74^{\mathrm{NS}}$ & $1,04 \mathrm{NS}$ \\
\hline & $C d R B$ 82-5336 & $0,07^{\mathrm{NS}}$ & $1,22^{\mathrm{NS}}$ & $0,70^{\mathrm{NS}}$ \\
\hline & $C d R B$ 83-5486 & $3,13^{*}$ & $1,30^{\mathrm{NS}}$ & 3,03 NS \\
\hline & $C d R B \quad 72-454$ & $0,30^{\mathrm{NS}}$ & $0,09^{\mathrm{NS}}$ & $0,41^{\mathrm{NS}}$ \\
\hline & $C d S P$ 79-1011 & $0,67^{\mathrm{NS}}$ & $0,26^{\mathrm{NS}}$ & $0,62^{\mathrm{NS}}$ \\
\hline & $C d S P 70-1143$ & $0,03^{\mathrm{NS}}$ & $0,11^{\mathrm{NS}}$ & $0,07^{\mathrm{NS}}$ \\
\hline & Cd SP 71-1406 & $5,70 * *$ & $0,46^{\mathrm{NS}}$ & $3,79^{*}$ \\
\hline & Cd SP 80-1842 & $0,85^{\mathrm{NS}}$ & $0,40^{\mathrm{NS}}$ & $0,16^{\mathrm{NS}}$ \\
\hline \multirow[t]{2}{*}{ C. V. (\%) } & Variedades & 12,06 & 9,36 & 8,81 \\
\hline & Condições & 11,03 & 8,01 & 10,40 \\
\hline \multirow[t]{2}{*}{ D. M. S } & Condições & 0,46 & 0,07 & 0,05 \\
\hline & $\mathrm{Cd}$ Variedade & 1,45 & 0,23 & 0,16 \\
\hline
\end{tabular}


Avaliação da seletividade da mistura de oxyfluorfen e ametryne, aplicada em pré ou pós-emergência, a dez variedades de cana-de-açúcar (cana-planta)

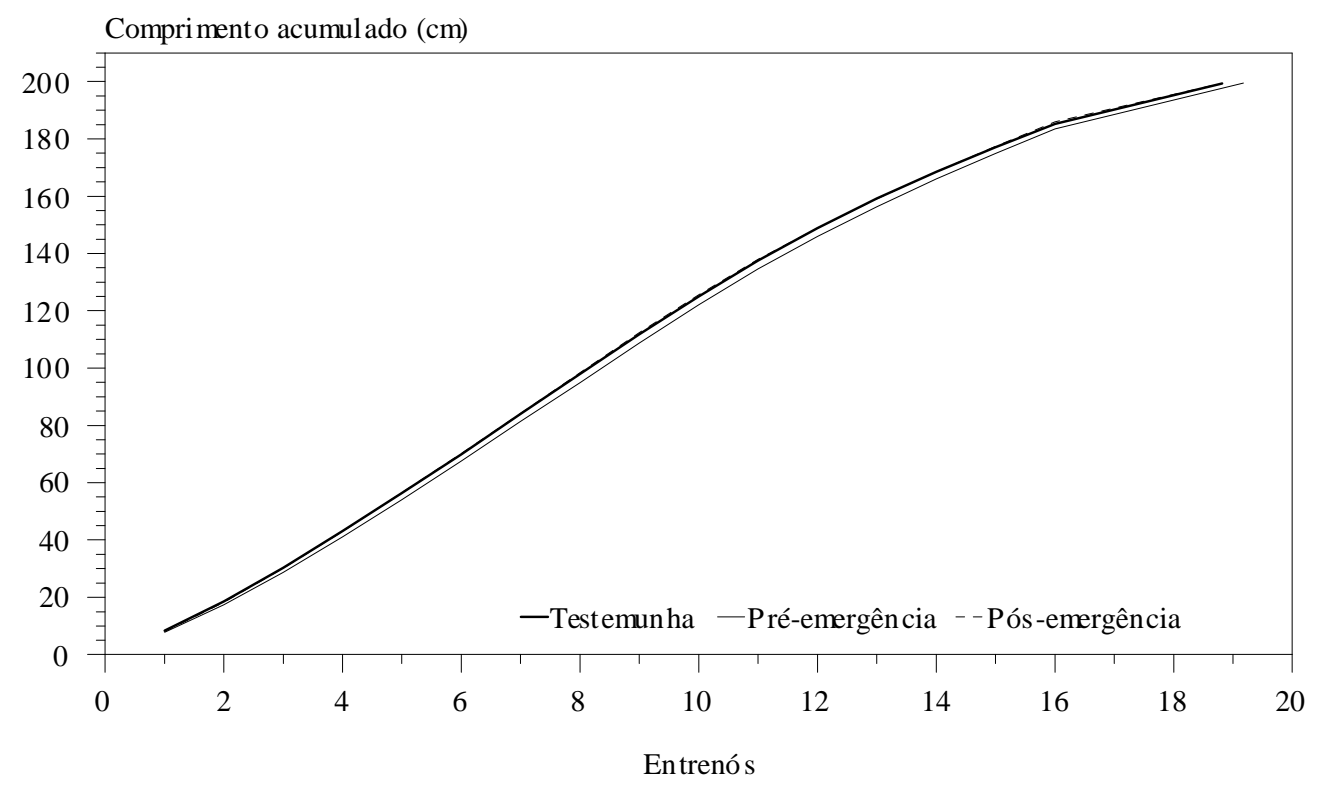

FIGURA 1. Comprimentos acumulados, até determinados entrenós, nas testemunhas e parcelas com aplicação dos herbicidas em pré ou pós-emergência. Médias de 600 valores, para as dez variedades estudadas.

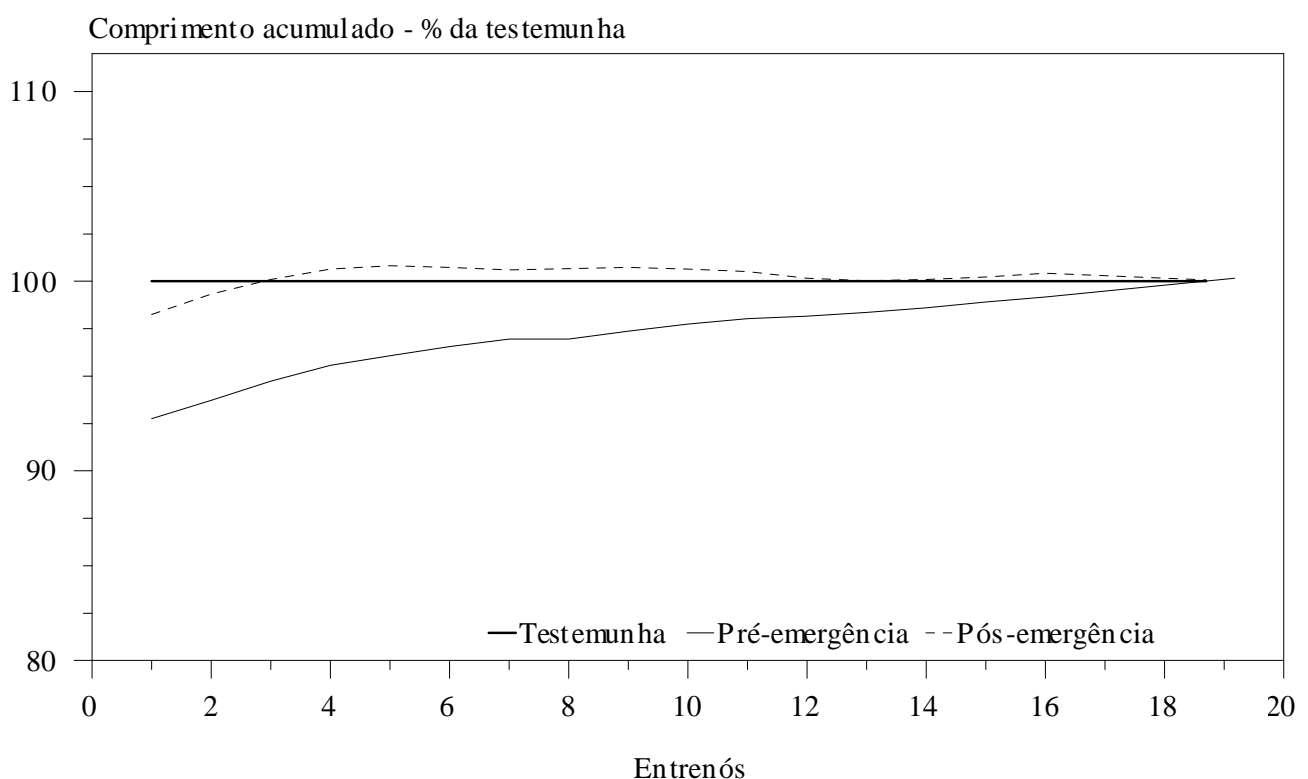

FIGURA 2. Comprimentos acumulados, até determinados entrenós, expressos em porcentagem dos valores encontrados nas testemunhas. Médias de 600 valores, para as dez variedades estudadas. 


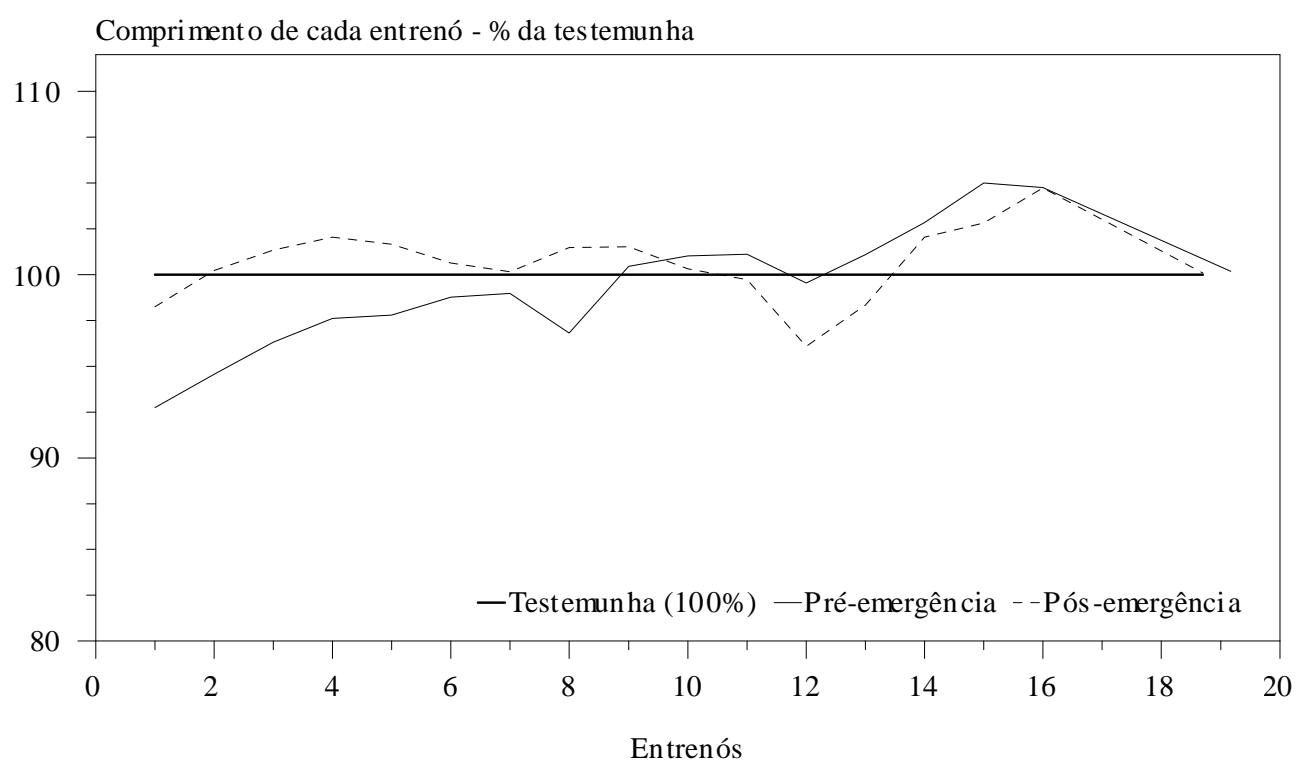

FIGURA 3. Comprimentos acumulados, até determinados entrenós, expressos em porcentagem dos valores encontrados nas testemunhas. Médias de 600 valores, para as dez variedades estudadas.

Considerando exclusivamente a Figura 3, fica evidente que nas parcelas com aplicação dos herbicidas, após uma redução inicial no comprimento de cada entrenó, houve uma compensação com a emissão de entrenós de maior comprimento alcançando-se, no final do experimento, comprimentos totais de colmos similares aos das parcelas testemunha. As reduções iniciais nos entrenós podem ser justificadas pelas injúrias dos herbicidas. $\mathrm{O}$ comprimento médio dos colmos na colheita foi de 1,$993 ; 1,995$ e $1,990 \mathrm{~m}$ para as testemunhas e parcelas com aplicação em pré e pós-emergência, respectivamente.

Não é tão simples, explicar o aumento do comprimento médio de alguns dos entrenós nas áreas tratadas. Inicialmente, os sintomas de intoxicação não ocorreram de modo uniforme em todas as plantas da culturas; dependendo do estágio das plantas no momento da aplicação, foi possível observar, em uma mesma parcela, plantas com altos níveis de intoxicação e plantas sem qualquer sintoma dos herbicidas. As maiores reduções na altura e no comprimento dos primeiros entrenós ocorreram nas plantas com maiores níveis de intoxicação. É provável que em determinados estágios, as plantas com menores níveis de intoxicação e maior comprimento, sombrearam as plantas mais intoxicadas e de menor porte, induzindo-as ao estiolamento e ao aumento do comprimento dos entrenós. Considerando que os valores apresentados são médias para 200 plantas, esta hipótese é coerente com a redução inicial associada com um posterior aumento do comprimento médio dos entrenós, nas parcelas tratadas.

$\mathrm{Na}$ Tabela 5, são apresentados os resultados referentes à produtividade de colmos, teor e produtividade de açúcar. Observa-se que, para as dez variedades, nenhuma destas características foi reduzida significativamente, em relação às testemunhas, pela aplicação da mistura oxyfluorfen e ametryne em pré ou pósemergência. 
TABELA 5. Resultados referentes à produtividade, de açúcar e colmos, e qualidade de colmos.

\begin{tabular}{|c|c|c|c|c|}
\hline Variedades & $\begin{array}{l}\text { Condições de } \\
\text { Aplicação }\end{array}$ & $\begin{array}{l}\text { Produtividade de } \\
\text { Colmos (t / ha) }\end{array}$ & Teor de açúcar (\%) & $\begin{array}{l}\text { Produtividade de } \\
\text { açúcar (t / ha) }\end{array}$ \\
\hline \multirow{3}{*}{ RB 83-5089 } & Testemunha & 107,25 & 16,58 & 16,68 \\
\hline & Pré-emergência & 105,55 & 16,35 & 17,09 \\
\hline & Pós-emergência & 104,45 & 16,75 & 18,17 \\
\hline \multirow{3}{*}{ RB 80-6043 } & Testemunha & 85,85 & 16,25 & 17,59 \\
\hline & Pré-emergência & 92,05 & 16,67 & 14,73 \\
\hline & Pós-emergência & 88,79 & 16,53 & 14,61 \\
\hline \multirow{3}{*}{ RB 78-5148 } & Testemunha & 92,20 & 16,10 & 14,63 \\
\hline & Pré-emergência & 99,37 & 15,77 & 15,61 \\
\hline & Pós-emergência & 95,20 & 15,98 & 14,49 \\
\hline \multirow{3}{*}{ RB 82-5336 } & Testemunha & 91,05 & 17,02 & 15,88 \\
\hline & Pré-emergência & 91,55 & 16,58 & 14,43 \\
\hline & Pós-emergência & 86,82 & 16,88 & 14,70 \\
\hline \multirow{3}{*}{ RB 83-5486 } & Testemunha & 85,05 & 17,31 & 14,75 \\
\hline & Pré-emergência & 89,20 & 18,16 & 16,83 \\
\hline & Pós-emergência & 94,45 & 18,41 & 17,64 \\
\hline \multirow{3}{*}{ RB 72-454 } & Testemunha & 94,95 & 17,07 & 16,26 \\
\hline & Pré-emergência & 98,87 & 17,08 & 16,54 \\
\hline & Pós-emergência & 100,62 & 16,95 & 16,83 \\
\hline \multirow{3}{*}{ SP 79-1011 } & Testemunha & 85,60 & 16,68 & 15,04 \\
\hline & Pré-emergência & 90,45 & 17,51 & 16,01 \\
\hline & Pós-emergência & 87,90 & 17,31 & 14,68 \\
\hline \multirow{3}{*}{ SP 70-1143 } & Testemunha & 76,25 & 17,57 & 12,96 \\
\hline & Pré-emergência & 78,62 & 17,65 & 13,52 \\
\hline & Pós-emergência & 79,05 & 17,72 & 13,77 \\
\hline \multirow{3}{*}{ SP 71-1406 } & Testemunha & 82,50 & 16,32 & 12,73 \\
\hline & Pré-emergência & 84,27 & 16,46 & 12,98 \\
\hline & Pós-emergência & 88,32 & 16,47 & 14,46 \\
\hline \multirow{3}{*}{ SP $80-1842$} & Testemunha & 85,12 & 17,05 & 13,63 \\
\hline & Pré-emergência & 89,09 & 17,14 & 14,60 \\
\hline & Pós-emergência & 81,42 & 17,15 & 13,67 \\
\hline \multirow{3}{*}{ Médias } & Testemunha & 88,58 & 16,89 & 14,71 \\
\hline & Pré-emergência & 91,90 & 16,94 & 15,24 \\
\hline & Pós-emergência & 90,70 & 17,01 & 15,31 \\
\hline \multirow{14}{*}{ Valores de F: } & Blocos & $5,57 * *$ & $0,55^{\mathrm{NS}}$ & $4,97 *$ \\
\hline & Variedades (V) & $7,75 * *$ & $14,50 * *$ & $6,76^{* *}$ \\
\hline & Condições (C) & $1,64^{\mathrm{NS}}$ & $0,60^{\mathrm{NS}}$ & $1,33^{\mathrm{NS}}$ \\
\hline & $\mathrm{V} \times \mathrm{C}$ & $0,42^{\mathrm{NS}}$ & $0,92^{\mathrm{NS}}$ & $0,68^{\mathrm{NS}}$ \\
\hline & $C d R B$ 83-5089 & $0,12^{\mathrm{NS}}$ & $0,66^{\mathrm{NS}}$ & $0,37^{\mathrm{NS}}$ \\
\hline & $C d R B$ 80-6043 & $0,56^{\mathrm{NS}}$ & $0,76^{\mathrm{NS}}$ & $0,50^{\mathrm{NS}}$ \\
\hline & $C d R B 78-5148$ & $0,75^{\mathrm{NS}}$ & $0,45^{\mathrm{NS}}$ & $0,48^{\mathrm{NS}}$ \\
\hline & $C d R B 82-5336$ & $0,39^{\mathrm{NS}}$ & $0,82^{\mathrm{NS}}$ & $0,76^{\mathrm{NS}}$ \\
\hline & $C d R B$ 83-5486 & $1,29^{\mathrm{NS}}$ & $5,28 * *$ & $2,85^{\mathrm{NS}}$ \\
\hline & $C d R B 72-454$ & $0,49^{\mathrm{NS}}$ & $0,08 \mathrm{NS}$ & $0,11^{\mathrm{NS}}$ \\
\hline & $C d S P 79-1011$ & $0,33^{\mathrm{NS}}$ & $0,54^{\mathrm{NS}}$ & $0,61^{\mathrm{NS}}$ \\
\hline & $C d S P 70-1143$ & $0,13^{\mathrm{NS}}$ & $0,09^{\mathrm{NS}}$ & $0,22^{\mathrm{NS}}$ \\
\hline & $C d S P$ 71-1406 & $0,52^{\mathrm{NS}}$ & $0,11^{\mathrm{NS}}$ & $1,12^{\mathrm{NS}}$ \\
\hline & Cd SP 80-1842 & $0,85^{\mathrm{NS}}$ & $0,06^{\mathrm{NS}}$ & $0,39^{\mathrm{NS}}$ \\
\hline \multirow[t]{2}{*}{ C. V. (\%) } & Variedades & 10,68 & 2,55 & 10,81 \\
\hline & Condições & 9,19 & 2,90 & 10,13 \\
\hline \multirow[t]{2}{*}{ D. M. S } & Condições & 3,72 & 0,23 & 0,80 \\
\hline & $\mathrm{C}$ d Variedade & 11,75 & 0,71 & 2,52 \\
\hline
\end{tabular}


Apesar da severidade inicial dos sintomas de intoxicação, a mistura oxyfluorfen e ametryne mostrou-se seletiva às dez cultivares testadas, tanto em pré quanto em pós-emergência, não sendo detectadas diferenças entre os tratamentos com ou sem uso de herbicidas em termos de produtividade de colmos, teor de açúcar nos colmos e produtividade de açúcar. Mesmo quando foram comparadas as médias para as dez variedades, não foi possível diferenciar a testemunha dos tratamentos com aplicação da mistura dos herbicidas oxyfluorfen e ametryne em pré ou pós emergência.

\section{LITERATURA CITADA}

CONSTANTIN, J. Avaliação da seletividade do herbicida halosulfuron à cana-deaçúcar. Botucatu, $1997 . \quad 71 p$. (Dissertação de Mestrado). Faculdade de
Ciências Agronômicas-UNESP.

RODRIGUES, B.N., ALMEIDA, F.S. Guia de herbicidas. Ed. autor, 1998. 648 p.

VELINI, E.D., FREDERICO, L.A., MORELLI, J.L., KOJIMA, K. Avaliação dos efeitos do herbicida clomazone, aplicado em pósemergência, sobre o crescimento e produtividade de soqueiras de nove cultivares de cana-de-açúcar. IN: $5^{\circ}$ CONGRESSO NACIONAL DA STAB. Águas de São Pedro - SP. 1993. p. 125-128.

VELINI, E.D.; FREDERICO, L.A.; ORSI JÚNIOR, F.; MORELLI, J.L. Avaliação dos efeitos do clomazone sobre o crescimento e produtividade de cana-deaçúcar (cana-planta CV. RB72454). IN: $6^{\circ}$ CONGRESSO NACIONAL DA STAB. Maceió - AL. 1996. p. 377-381. 